\title{
Gerontology
}

\section{Prevalence of Percutaneous Endoscopic Gastrostomy in Nursing Home Residents - A Nationwide Survey in Germany}

\author{
R. Wirth ${ }^{a} \quad$ J.M. Bauer ${ }^{b} \quad$ H.P. Willschrei ${ }^{c}$ D. Volkert ${ }^{b} \quad$ C.C. Sieber ${ }^{b}$ \\ ${ }^{a}$ Department of Internal Medicine and Geriatrics, St. Marien Hospital Borken, Borken, ${ }^{\mathrm{b}}$ Chair of Geriatric Medicine, \\ Friedrich Alexander University Erlangen-Nuremberg and Department of Internal Medicine II, Nuremberg Hospital, \\ Nuremberg, and 'Department of Geriatric Rehabilitation, St. Marienhospital Orsoy, Rheinberg, Germany
}

\section{Key Words}

Enteral nutrition $\cdot$ Nursing home $\cdot$ Percutaneous

endoscopic gastrostomy $\cdot$ Tube feeding

\begin{abstract}
Background: Despite extensive discussion about percutaneous endoscopic gastrostomy (PEG) in nursing home residents, no prevalence data exist in most countries. Objective: This study aimed to determine the prevalence of PEG in German nursing homes, as well as nursing home characteristics that may influence this prevalence. Additionally, we documented the timing of PEG insertion, whether pre- or postadmission to the nursing home, and the proportion of residents receiving oral nutrition in addition to tube feeds. Methods: A 26-item questionnaire was sent to 6,995 German nursing homes. Responses were anonymous. Results: Of the 6,995 questionnaires sent out, 807 (11.5\%) were completed and returned. Of the 66,507 total residents in the responding nursing homes, there were 4,390 residents with PEG (6.6\%). The median PEG prevalence was 5.6\% (5th-95th percentile 1.0-16.3\%). Of all PEGs inserted, $55.3 \%$ were inserted before and $44.7 \%$ were inserted after nursing home admission. Oral beverage intake in addition to tube feeding
\end{abstract}

was reported in $48.8 \%$ of residents with a PEG, and $43.5 \%$ of patients also received solid food. There were no significant differences in PEG prevalence between the federal states of Germany. The location (rural vs. urban) of the nursing home, its proprietor and food delivery method had no significant influence on PEG prevalence. With regard only to PEG tubes inserted after nursing home admission, all the factors stated above showed no significant influence on PEG prevalence. Weak positive correlations between PEG prevalence and the size of the nursing home as well as the number of total and certified nursing staff per resident could be detected, reflecting the heavy burden of care associated with residents requiring artificial nutrition. Conclusions: Compared to other countries, Germany can be assumed to have an average PEG prevalence in nursing home residents. No specific nursing home characteristics could be identified that affect PEG prevalence.

Copyright $\odot 2009$ S. Karger AG, Basel

This work was supported in part by a generous grant from Pfrimmer Nutricia, who provided postage for the questionnaires.

\section{KARGER}

Fax +4161306 1234

E-Mail karger@karger.ch

www.karger.com (c) 2009 S. Karger AG, Basel

0304-324X/10/0564-0371\$26.00/0

Accessible online at:

www.karger.com/ger
R. Wirth

Department of Internal Medicine and Geriatrics, St. Marien Hospital Borken DE-46325 Borken (Germany)

Tel. +492861973 410, Fax +492861975 3410

E-Mail rainer.wirth@ hospital-borken.de 


\section{Introduction}

Due to its high prevalence and serious sequelae in the geriatric population [1], malnutrition is a major health concern [2]. Its nutritional treatment ranges from dietary modification, food fortification and supplementation to tube feeding and parenteral nutrition. Enteral nutrition via percutaneous endoscopic gastrostomy (PEG) is a safe and widely accepted method for administering long-term enteral nutrition. It was first introduced by Gauderer et al. [3] in pediatrics. Previously, it was used more frequently for other patients and indications, whereas these days it is thought to be used predominantly for elderly patients [4]. In the United States, $1.6 \%$ of all dementia patients aged 60 and older receive a PEG tube [5]. In German nursing homes, tube feeding is exclusively done via PEG [6]. PEG placement in Germany is estimated to be performed approximately 140,000 times a year, with presumably $70 \%$ of those placed being for nursing home residents [7]. Nevertheless, reliable data are lacking in Germany and other European countries regarding the prevalence and use of enteral feeding via PEG in nursing homes. Significant differences between countries are thought to exist $[8,9]$. PEG use in nursing homes is a field of high interest because critics of artificial nutrition in the elderly presume that this method is partly misused to ease care without any reasonable medical indication [10-13]. The use of feeding tubes in advanced dementia is a constant point of debate, especially since here are no sufficient data about the advantages of tube feeding for this population. However, as retrospective data do not suggest any benefit [14], current guidelines do not recommend the use of tube feeding in advanced dementia [15].

In light of this extensive discussion, it is surprising that there are no reliable data about the prevalence of tube feeding in nursing home residents in Germany and most other European countries. Only a regional study from Bremen presents data describing the prevalence of PEG in its nursing homes [16]. In that study, the prevalence of PEG tubes in 56 nursing homes in Bremen with 4,300 residents was higher than expected, varying from 0 to $16.7 \%$ with a mean of $7.8 \%$. A nationwide benchmarking study in the Netherlands identified the prevalence of tube feeding in nursing homes to be only $2.0 \%$ in 2007 [17]. The corresponding use of PEG tubes may be even lower than this reported rate. Data regarding feeding tube use in US nursing homes suggest that its prevalence is not only associated with the clinical characteristics of residents, but is also independently associated with the fiscal, organizational and demographic features of the nursing home [18-21]. The prevalence of PEG tubes in German nursing homes is unknown, and the effect of institutional level factors on its use is unclear. The following survey was conducted in order to determine the prevalence of PEG tubes in German nursing homes, factors influencing their use, the timing of PEG insertion (before or after admission), and the proportion of residents receiving oral nutrition in addition to tube-feeding.

\section{Methods}

In November 2007, an anonymous nationwide postal survey was conducted using a standardized, two-sided, 26-item questionnaire, taking into consideration the institution, the staff, nursing home residents in general as well as residents with PEG. This questionnaire was sent by mail to the management of 6,995 nursing homes in Germany for whom address data were available. The manager of the institution or alternatively the manager of the nursing staff was asked to complete the questionnaire. Completion of the questionnaire took about 10-15 min, as by marking a cross or inserting numbers one could easily answer all questions. Questions about the federal state, the proprietor of the nursing home, the size of the city, the number of residents and nursing places, the number and qualifications of the nursing staff, the system of hot meal supply, the number and age of residents with PEG, the level of need of nursing care of residents with PEG, the number of residents with PEG inserted before and after nursing home admission, the number of residents with oral intake of beverages or solid food in addition to tube feeding, and the estimated proportion of deliberate PEG removal due to lack of use were included. The validity of the questionnaire was tested in 3 nursing homes before starting the study.

All data analysis was performed using SPSS version 16 (SPSS Inc, Chicago, Ill., USA). Descriptive statistics were used to calculate item frequency, mean, standard deviation, median, quartiles and percentiles. Correlation analysis was done using Spearman's rank correlation coefficient. Kruskal-Wallis analysis was used for group comparisons of PEG prevalence. A p value of $<0.05$ was considered statistically significant. The study was performed according to the Helsinki Declaration for human studies and in accordance with the regulations of German ethical committees.

\section{Results}

Of the 6,995 questionnaires sent out, 812 (11.6\%) were returned. Five questionnaires lacking data about PEG prevalence were excluded from the analysis, so that 807 (11.5\%) questionnaires were available for analysis.

The response rate was proportional to the population of all federal states. Characteristics of the participating nursing homes, specifically the size of the city in which it is located, its proprietor and hot-meal food supply are summarized in table 1 . A mean of $82.4 \pm 46.0$ residents 
Table 1. Characteristics of participating nursing homes $(n=807)$ and PEG prevalence

\begin{tabular}{|c|c|c|c|}
\hline & $\mathrm{n}(\%)$ & $\begin{array}{l}\text { PEG preva- } \\
\text { lence, } \%^{a}\end{array}$ & $\begin{array}{l}\mathrm{p} \\
\text { value }^{\mathrm{b}}\end{array}$ \\
\hline \multicolumn{4}{|c|}{ Size of city of nursing home location, number of inhabitants } \\
\hline$<50,000$ & $510(63.2)$ & 5.5 & \\
\hline $50,000-150,000$ & $125(15.5)$ & 5.8 & \\
\hline$>150,000$ & $151(18.7)$ & 5.7 & \\
\hline No data & $21(2.6)$ & 5.8 & 0.89 \\
\hline \multicolumn{4}{|c|}{ Proprietor of the nursing home } \\
\hline Private & $295(36.6)$ & 6.1 & \\
\hline Church & $272(33.7)$ & 5.4 & \\
\hline Community & $76(9.4)$ & 5.3 & \\
\hline Other & $142(17.6)$ & 5.7 & \\
\hline No data & $22(2.7)$ & 5.3 & 0.29 \\
\hline \multicolumn{4}{|l|}{ Hot-meal food supply } \\
\hline Own kitchen & $607(75.2)$ & 5.6 & \\
\hline External kitchen & $132(16.4)$ & 5.8 & \\
\hline Instant meals & $24(3.0)$ & 6.3 & \\
\hline Other & 15 (1.9) & 8.3 & \\
\hline No data & $29(3.6)$ & 3.9 & 0.42 \\
\hline
\end{tabular}

Table 2. Characteristics of nursing home residents with PEG ( $\mathrm{n}=$ $4,390)$

\begin{tabular}{lc}
\hline & $\mathrm{n}(\%)$ \\
\hline Age & \\
$\quad<60$ years & $421(9.6)$ \\
$\quad 60-80$ years & $1,633(37.2)$ \\
$\quad>80$ years & $2,133(48.6)$ \\
$\quad$ No data & $203(4.6)$ \\
\hline Time of PEG insertion & \\
$\quad$ Before nursing home admission & $2,239(51.0)$ \\
$\quad$ After nursing home admission & $1,812(41.3)$ \\
$\quad$ No data & $339(7.7)$ \\
\hline Additional oral intake of solid food & \\
$\quad$ Yes & $1,596(36.4)$ \\
$\quad$ No & $2,077(47.3)$ \\
$\quad$ No data & $717(16.3)$ \\
\hline Additional oral intake of liquids & \\
$\quad$ Yes & $1,918(43.7)$ \\
No & $2,011(45.8)$ \\
No data & $461(10.5)$ \\
\hline
\end{tabular}

Midfield PEG Prevalence in German Nursing Homes

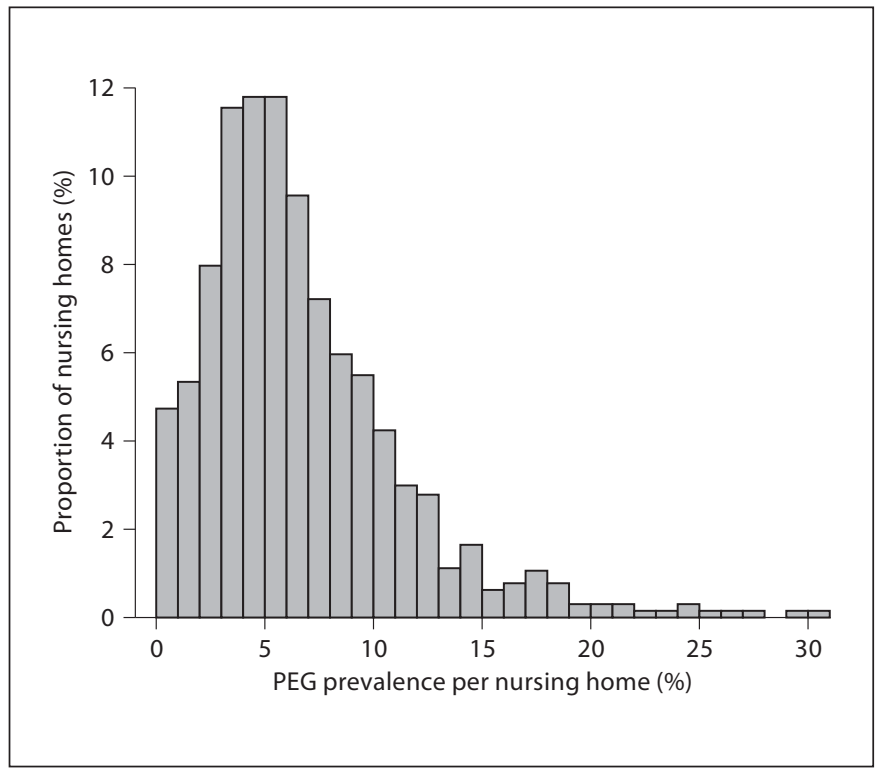

Fig. 1. Distribution of PEG prevalence in German nursing homes $(\mathrm{n}=807)$.

were reported to be living in the participating nursing homes. From the 724 nursing homes reporting data regarding nursing staff, a mean of $0.49 \pm 0.17$ total nursing staff per resident and $0.23 \pm 0.10$ certified nurses per resident were calculated.

In all 807 analyzed nursing homes, there were 4,390 of 66,507 residents living with a PEG (6.6\%). The median PEG prevalence was 5.6\% (5th-95th percentile 1.0-16.3\%). A total of 32 nursing homes (4.0\%) declared having no residents with a PEG. A PEG prevalence of $<3.7 \%$ was reported in $25 \%$ of all nursing homes, and $25 \%$ of homes had a prevalence of $>8.8 \%$ (fig. 1 ). There were also some extreme values, such as 3 nursing homes with PEG prevalences of $49.3,66.1$ and $94.7 \%$. Due to the specialties of these nursing homes, such as post-neurosurgical care, most of the residents with PEG in these institutions were under 60 years old.

The main characteristics of the nursing home residents with PEG are shown in table 2. Of all PEGs, 2,239 (51.0\%) were inserted before nursing home admission, and 1,812 (41.3\%) PEGs were inserted after nursing home admission. For 339 (7.7\%) subjects with PEG, the data on PEG insertion were not available. Considering only the 4,051 PEG residents for whom the data were available, $55.3 \%$ of PEG insertions were done before and $44.7 \%$ after the nursing home admission. The median prevalence of PEGs inserted after nursing home admission was $2.0 \%$ of 
all residents (5th-95th percentile $0.0-10.1 \%$ ). Of all nursing homes, $25 \%$ had no PEGs inserted after nursing home admission, and $25 \%$ had a prevalence of PEG insertion after admission of $>4.4 \%$ of their residents.

Oral intake of solid food in addition to tube feeding was reported in 1,596 (36.4\%) residents, no intake of solid food was reported in 2,077 (47.3\%) residents. For 717 (16.3\%) PEG residents data was not available on food intake. Oral fluid intake in addition to tube feeds was reported for 1,918 (43.7\%) nursing home residents, no oral fluid intake was reported for 2,011 (45.8\%) residents and there were no data available for 461 (10.5\%) residents (table 2). In considering only those residents for whom these data were available, the oral intake of beverages was reported for $48.8 \%$ of the patients and oral intake of solid food was reported for $43.5 \%$ of patients in addition to tube feeding.

Of all homes responding, 241 (30.4\%) claimed to not have experienced any deliberate PEG removal in the past, and 552 (69.6\%) nursing homes declared experiencing PEG removal, with a mean estimated proportion of $13.8 \%$ of all PEGs. Considering all nursing homes, a mean estimated PEG removal rate of $9.6 \pm 16.9 \%$ was calculated.

Median PEG prevalence in the federal states of Germany ranged from 3.3\% in Bremen to $9.0 \%$ in Thüringen, without significant differences between the states (table 3; fig. 2). Location in a rural or urban area had no influence on PEG prevalence. No differences in PEG prevalence in nursing homes were found between nursing homes with a community, church, private or unknown proprietor. Furthermore, there were no differences in PEG prevalence according to the food delivery system (table 1). The rate of PEG tube insertion after nursing home admission showed no significant influence on PEG prevalence (data not shown).

There was a very weak correlation between PEG prevalence and the number of residents $(r=0.09 ; \mathrm{p}=0.009)$. In addition, there was a weak correlation between PEG prevalence and the number of total nursing staff per resident $(r=0.17 ; p<0.001)$, as well as the number of certified nursing staff per resident $(r=0.13 ; p=0.001)$. This suggests that nursing homes with a greater number of nursing staff per resident and higher nursing qualifications had a higher PEG prevalence and vice versa. In the German nursing system, residents are categorized according to three levels of care needed, with level III reflecting the highest need. There was a significant correlation between PEG prevalence and the number of residents requiring care level III $(\mathrm{r}=0.38 ; \mathrm{p}<0.001)$.

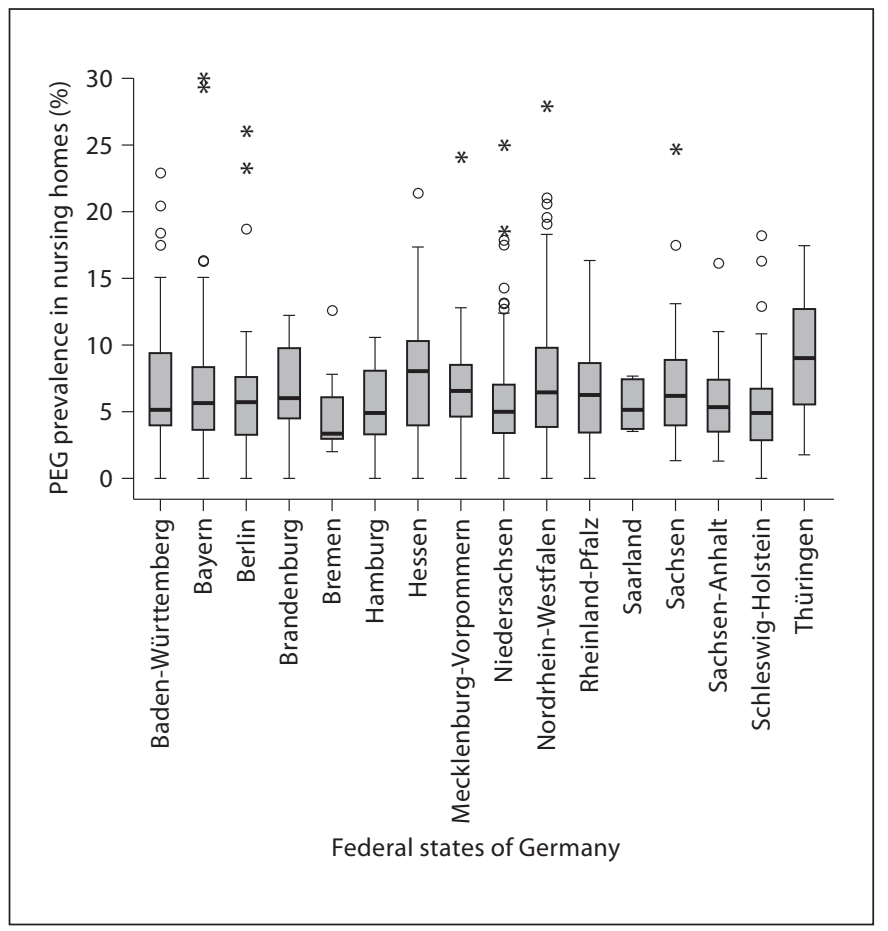

Fig. 2. $P E G$ prevalence in nursing homes in the federal states of Germany (box plots with median, interquartile range, minimum, maximum, outliers $(\bigcirc)$ and extreme values $\left(^{*}\right)$. For data in each federal state see table 3.

Table 3. PEG prevalence in federal states of Germany

\begin{tabular}{lccc}
\hline \multirow{2}{*}{ Federal state } & \multirow{2}{*}{$\begin{array}{c}\text { Participating } \\
\text { nursing } \\
\text { homes, } \mathrm{n}(\%)\end{array}$} & PEG prevalence, \% \\
\cline { 3 - 4 } & & & \\
& & & \\
& & & \\
& $149(12.0)$ & $6.6 \pm 4.5$ & \\
Baden-Württemberg & $6.5 \pm 5.2$ & 5.1 \\
Bayern & $19(2.4)$ & $7.7 \pm 7.3$ & 5.7 \\
Berlin & $18(2.2)$ & $8.7 \pm 10.7$ & 6.0 \\
Brandenburg & $8(1.0)$ & $4.9 \pm 3.7$ & 3.3 \\
Bremen & $12(1.5)$ & $5.4 \pm 3.2$ & 4.9 \\
Hamburg & $54(6.7)$ & $8.7 \pm 9.2$ & 8.0 \\
Hessen & $22(2.7)$ & $11.1 \pm 19.3$ & 6.5 \\
Mecklenburg-Vorpommern & $106(13.1)$ & $6.0 \pm 4.3$ & 5.1 \\
Niedersachsen & $147(18.2)$ & $7.6 \pm 5.5$ & 6.4 \\
Nordrhein-Westfalen & $36(4.5)$ & $5.9 \pm 3.6$ & 6.2 \\
Rheinland-Pfalz & $5(0.6)$ & $5.5 \pm 2.0$ & 5.2 \\
Saarland & $46(5.7)$ & $7.0 \pm 4.4$ & 6.2 \\
Sachsen & $26(3.2)$ & $5.6 \pm 3.2$ & 5.3 \\
Sachsen-Anhalt & $47(5.8)$ & $6.2 \pm 6.5$ & 4.9 \\
Schleswig-Holstein & $15(1.9)$ & $10.8 \pm 8.6$ & 9.0 \\
Thüringen & $807(100)$ & 6.6 & 5.6 \\
Total & & & \\
\hline
\end{tabular}

p value from Kruskal-Wallis analysis: 0.19 . 


\section{Discussion}

In light of the extensive ongoing discussion in medical journals and newspapers regarding the rationale of tube feeding in nursing home residents, it is astonishing that there are no reliable data about PEG prevalence in nursing home residents in most countries, including Germany. This report is the first study investigating PEG prevalence and possibly influential nursing home characteristics in Germany. By receiving data of 807 nursing homes containing 66,507 residents, this study covered $9.9 \%$ of all 671,080 full-time nursing home residents in Germany in 2007. The characteristics of the nursing homes analyzed in this study were comparable to the overall German nursing home statistics in 2007 [22]. For example, there were 0.49 nursing staff/resident in the homes in our study as compared to 0.51 nationally, 0.23 certified nursing staff/resident versus 0.26 nationally, $37 \%$ were private versus $40 \%$ nationally, $9 \%$ were community-based versus $6 \%$ nationally, and $51 \%$ were church- or other proprietorbased versus $47 \%$ nationally. Only the mean number of residents was significantly larger in this study compared to national levels ( $82 \mathrm{vs.} 67$ ), perhaps indicating that larger nursing homes were more willing to take part in this survey.

The mean (6.6\%) and median (5.6\%) PEG prevalence in this survey differed due to a non-normal distribution of PEG prevalence in nursing homes. In general, the PEG prevalence in this study is lower than the $7.8 \%$ mean PEG prevalence obtained in a previous regional study in Germany [15], but barely higher than the prevalence of 5.9\% described in the data from the 'NutritionDay in nursing homes 2007' [23] of 2,137 residents in 8 Austrian and 30 German nursing homes. For European comparisons, there is only one national Dutch study available, with a tube feeding prevalence in nursing homes of $2.0 \%$ in 2007 [17]. A small-scale study from Italy declared the prevalence of tube feeding to range between $<2.0 \%$ up to $6.6 \%$ in a few nursing homes, but did not mention a mean or median prevalence [9]. On a global scale, there are several studies comparing the use and prevalence of tube feeding in nursing home residents with advanced dementia [24], which unfortunately are not comparable to this study as our questionnaire was not restricted to residents with dementia. One study comparing the general prevalence of tube feeding in nursing homes in Iceland, the Canadian province of Ontario and the US state of Missouri points out distinctive international differences in the prevalence of tube feeding. This minimum data set analysis from 1998 showed a prevalence of tube feeding of $15.1 \%$ in Canadian, $4.6 \%$ in American and $1.3 \%$ in Icelandic nursing homes [7]. Although it is necessary to be cautious when interpreting these data because of different periods of data acquisition, as well as differences in methodology and the nursing home care system between countries, it can be assumed that Germany has an average PEG prevalence in its nursing homes. Considering a total of 671,080 nursing home residents in 9,919 German nursing homes in 2007 [22], a conservative calculation of a median PEG prevalence of 5.6\% suggests a total of 37,580 nursing home residents with PEG in Germany. An extreme projection of a mean PEG prevalence of $6.6 \%$ creates an estimate of 44,291 nursing home residents with PEG in Germany. In summary, roughly 40,000 nursing home residents are presently living with PEG in Germany. This estimate is inconsistent with the recent assertion that $70 \%$ of the estimated 140,000 PEGs inserted annually are going into nursing home residents in Germany [7, 12]. On the one hand, the assertion of 140,000 PEGs being annually inserted in Germany might be an overestimation, as it is only a rough estimate obtained from PEG sales figures. On the other hand, 70\% of these PEGs might be inserted in elderly patients who do not all reside in nursing homes.

One study comparing the tube feeding prevalence in different counties of Kansas in the United States showed considerable differences in the prevalence of tube feeding in urban (19.3\%), midsized (8.0\%) and rural (6.4\%) counties [21]. Furthermore, use of feeding tubes in US nursing homes is not only associated with the clinical characteristics of the residents, but also depends on the fiscal, organizational and demographic features of the nursing homes $[18,19]$. It was therefore of interest to analyze PEG prevalence in relation to nursing home size, proprietor, location and food delivery system. None of these abovementioned relationships were evident in our study and cannot be confirmed for German nursing homes.

Many journal letters and articles denounce PEG feeding in the elderly as a method of relieving nursing staff [12]. In this study, only $44.7 \%$ of all PEGs were inserted after nursing home admission and could therefore possibly be influenced by the nursing home. The median prevalence of PEGs inserted after nursing home admission was only $2.0 \%$, meaning that $50 \%$ of the nursing homes surveyed had a PEG insertion in $<2.0 \%$ of their residents during their nursing home stay. On the other hand, PEG prevalence might be influenced by the unreasonable behavior of some nursing homes in only admitting undernourished patients with prior PEG insertion. Furthermore, the number of nursing staff showed a mi- 
nor positive correlation with PEG prevalence. These data do not necessarily support the assumption that PEG feeding is a method for relieving nursing staff. If so, nursing homes with less nursing staff would have a larger PEG prevalence, representing an inverse correlation. The weak positive correlation between PEG prevalence and the number of nursing staff per resident can be attributed to the heavy burden of care required for nursing home residents needing artificial nutrition. This assumption is supported by the positive correlation of PEG prevalence with the number of residents requiring a high level of care. These data are definitely inconsistent with the assumption that PEGs are mainly inserted to relieve the burden on nursing staff. Apart from this, the high prevalence of subjects with oral intake of beverages and/or solid food in addition to tube feeding gives rise to the suspicion that a considerable proportion of those fed via PEG are at least in moderate health.

PEG tubes are mostly inserted during a hospital stay before as well as after the nursing home admission. If the prevalence of PEG insertions is deemed too high, we propose focusing on altering the hospital stay to reduce the number of insertions. In support of this claim, Monteleoni et al. [25] were able to show that a palliative care consulting team combined with an educational program can reduce the number of feeding tube insertions.

There are some limitations to this study. First, it is a survey, which has the potential to accrue inaccurate data. Second, the response rate was fairly low, and there could be a participation bias for institutions with a special interest in nutritional care. A further limitation is that information about cognitive function, the main underlying disease of nursing home residents with PEG, as well as the reasons for PEG insertion and removal are missing. We would strongly recommend the inclusion of this information in any further study on this topic. One advantage of this study is its nationwide scope, the considerable number of nursing homes included, and the fact that these homes have primary characteristics comparable to national nursing home data. A second advantage is that this is the first study in Germany investigating nursing home characteristics as possible factors influencing PEG placement and use.

\section{Conclusions}

Compared to other countries, Germany is projected to have an average PEG prevalence in nursing home residents. PEG prevalence was found to be independent of the federal state, the rural or urban location, the proprietor, and the food delivery system of the nursing home. Similarly, no influencing factors on the prevalence of PEG tubes inserted after nursing home admission could be determined. The minor positive correlation between PEG prevalence and number of nursing staff per resident can be attributed to the heavy burden of care for nursing home residents requiring artificial nutrition, and contradicts the assumption that PEG is often being misused to ease care.

The authors hope that this investigation will stimulate other scientists to measure the prevalence of tube feeding and PEG tubes in nursing homes, as done in the yearly repeated 'NutritionDay' [23] and 'LPZ' [17]. We hope this study will encourage nursing home managers to take part in such surveys, such that a European and global comparison can be conducted in the future. This survey thus provides important hints regarding many aspects of PEG use in the nursing home population in Germany and may also serve as benchmark for other European countries.

\section{References}

1 Pirlich M, Schütz T, Norman K, Gastell S, Lübke HJ, Bischoff SC, Bolder U, Frieling T, Güldenzoph H, Hahn K, Jauch KW, Schindler K, Stein J, Volkert D, Weimann A, Werner H, Wolf C, Zürcher G, Bauer P, Lochs H: The German hospital malnutrition study. Clin Nutr 2006;25:563-572.
2 Arvanitakis M, Beck A, Coppens P, De Man F, Elia M, Hebuterne X, Henry S, Kohl O, Lesourd B, Lochs H, Pepersack T, Pichard C, Planas M, Schindler K, Schols J, Sobotka L, Van Gossum A: Nutrition in care homes and home care: how to implement adequate strategies (report of the Brussels Forum (2223 November 2007)). Clin Nutr 2008;27: 481-488.

3 Gauderer MW, Ponsky JL, Izant RJ Jr: Gastrostomy without laparotomy: a percutaneous endoscopic technique. J Pediatr Surg $1980 ; 15: 872-875$.
4 Gauderer MW: Percutaneous endoscopic gastrostomy and the evolution of contemporary long-term enteral access. Clin Nutr 2002;21:103-110.

5 Braun UK, Rabeneck L, McCullough LB, Urbauer DL, Wray NP, Lairson DR, Beyth RJ: Decreasing use of percutaneous endoscopic gastrostomy tube feeding for veterans with dementia - racial differences remain. J Am Geriatr Soc 2005;53:242-248. 
6 Bucher H, Hufnagel G: Sondenernährung: Versorgungslage ist defizitär. Dtsch Ärztebl 2004; 101:246.

7 Eibach U, Zwirner K: Parenteral nutrition: at what price? An ethical orientation to 'percutaneous endoscopic gastrostomy' (PEG catheter) nutrition (in German). Med Klin 2002; 97:558-563.

8 Jensdóttir $A B$, Rantz M, Hjaltadóttir I, Guodmundsdòttir, Rook M, Grando MES, Grando V: International comparison of quality indicators in United States, Icelandic and Canadian nursing facilities. Int Nurs Rev 2003;50:79-84.

9 Bellelli G, Frisoni GB, Trabucchi M: Feeding tube use in Italian nursing homes: the role of cultural factors. J Am Med Dir Assoc 2005; 6:87-88.

10 Li I: Feeding tubes in patients with severe dementia. Am Fam Physician 2002;65:16051610.

11 Skelly RH: Are we using percutaneous endoscopic gastrostomy appropriately in the elderly? Curr Opin Clin Nutr Metab Care 2002;5:35-42.

12 Strätling MSP, Bartmann FJ: Künstliche Ernährung - Gut gemeint ist nicht immer gut gemacht. Dtsch Ärztebl 2005;102:21532154.

13 Cervo FA, Bryan L, Farber S: To PEG or not to PEG: a review of evidence for placing feeding tubes in advanced dementia and the decision-making process. Geriatrics 2006;61:3035.
14 Murphy LM, Lipman TO: Percutaneous endoscopic gastrostomy does not prolong survival in patients with dementia. Arch Intern Med 2003;163:1351-1353.

15 Volkert D, Berner YN, Berry E, Cederholm T, Coti Bertrand P, Milne A, Palmblad J, Schneider S, Sobotka L, Stanga Z; DGEM (German Society for Nutritional Medicine), Lenzen-Grossimlinghaus R, Krys U, Pirlich M, Herbst B, Schütz T, Schröer W, Weinrebe W, Ockenga J, Lochs H; ESPEN (European Society for Parenteral and Enteral Nutrition): ESPEN Guidelines on Enteral Nutrition: Geriatrics. Clin Nutr 2006;25:330360.

16 Becker W, Hilbert T: Gastrostromy tube feeding of elderly inpatients in Bremen (in German). Gesundheitswesen 2004;66:806811.

17 Halfens RJG MJ, Neyens JCL, Offermanns MPW: Universiteit Maastricht, Department of Health Care and Nursing Sciences: Landelijke Prevalentiemeting Zorgproblemen [National Prevalence Measurement of Care Problems], Rapportage Resultaten 2007 [http://www.lpz-um.nl], 2007.

18 Mitchell SL, Teno JM, Roy J, Kabumoto G, Mor V: Clinical and organizational factors associated with feeding tube use among nursing home residents with advanced cognitive impairment. JAMA 2003;290:73-80.

19 Mitchell SL, Kiely DK, Gillick MR: Nursing home characteristics associated with tube feeding in advanced cognitive impairment. J Am Geriatr Soc 2003;51:75-79.
20 Ahronheim JC, Mulvihill M, Sieger C, Park P, Fries BE: State practice variations in the use of tube feeding for nursing home residents with severe cognitive impairment. J Am Geriatr Soc 2001;49:148-152.

21 Gessert CE, Calkins DR: Rural-urban differences in end-of-life care: the use of feeding tubes. J Rural Health 2001;17:16-24.

22 Statistisches Bundesamt: Pflegestatistik 2007 - Pflege im Rahmen der Pflegeversicherung. 4. Bericht: Ländervergleich - Pflegeheime (German nursing home statistics, 2007). Wiesbaden, Statistisches Bundesamt, 2008.

23 Valentini L, Schindler K, Schlaffer R, Bucher $\mathrm{H}$, Mouhieddine M, Steininger K, Tripamer J, Handschuh M, Schuh C, Volkert D, Lochs H, Sieber CC, Hiesmayr M: The first nutritionDay in nursing homes: participation may improve malnutrition awareness. Clin Nutr 2009;28:109-116.

24 Teno J, Mor V, DeSilva D, Kabumoto G, Roy $\mathrm{J}$, Wetle T: Use of feeding tubes in nursing home residents with severe cognitive impairment. JAMA 2002;287:3211-3212.

25 Monteleoni C, Clark E: Using rapid-cycle quality improvement methodology to reduce feeding tubes in patients with advanced dementia: before and after study. BMJ 2004; 329:491-494 